\title{
Emerging pharmacotherapy of tinnitus
}

\author{
Berthold Langguth, \\ Department of Psychiatry and Psychotherapy, University of Regensburg, Germany; Interdisciplinary \\ Tinnitus Clinic, University of Regensburg, Germany. University of Regensburg, \\ Universitaetsstraße 84, 93053 Regensburg, Germany, Phone: +49-941-941 2099, Fax: \\ +49-941-941 2025
}

Richard Salvi, and

Center for Hearing and Deafness, Department of Communicative Disorders and Sciences, University at Buffalo, Center for Hearing and Deafness, 137 Cary Hall, Buffalo, NY 14214, Phone: 716829 5310, Fax: 7168292980

\section{Ana Belén Elgoyhen}

Instituto de Investigaciones en Ingeniería Genética y Biología Molecular, Consejo Nacional de Investigaciones Científicas y Técnicas, Buenos Aires 1428, Argentina. Departamento de Farmacología, Facultad de Medicina, Universidad de Buenos Aires, Buenos, Aires 1121, Argentina, Instituto de Investigaciones en Ingeniería Genética y Biologia Molecular, (INGEBI-CONICET), Vuelta de Obligado 2490, 1428 Buenos Aires, Argentina; phone: +54114 7832871; fax: +54114 7868578

Berthold Langguth: Berthold.Langguth@medbo.de; Richard Salvi: salvi@buffalo.edu; Ana Belén Elgoyhen: elgoyhen@dna.uba.ar

\section{Abstract}

Tinnitus, the perception of sound in the absence of an auditory stimulus, is perceived by about one in 10 adults, and for at least 1 in 100, tinnitus severely affects their quality of life. Since tinnitus is frequently associated with irritability, agitation, stress, insomnia, anxiety and depression, the social and economic burdens of tinnitus can be enormous. No curative treatments are available. However, tinnitus symptoms can be alleviated to some extent. The most widespread management therapies consist of auditory stimulation and cognitive behavioural treatment, aiming at improving habituation and coping strategies. Available clinical trials vary in methodological rigor and have been performed for a considerable number of different drugs. None of the investigated drugs have demonstrated to provide replicable long-term reduction of tinnitus impact in the majority of patients, in excess of placebo effects. Accordingly, there are no FDA- or EMEA-approved drugs for the treatment of tinnitus. However, in spite of the lack of evidence, a large variety of different compounds are prescribed off-label. Therefore, more effective pharmacotherapies for this huge and still growing market are desperately needed and even a drug that produces only a small but significant effect would have an enormous therapeutic impact. This review describes current and emerging pharmacotherapies with its current difficulties and limitations. In addition, it provides an estimate of the tinnitus market. Finally, it describes recent advances in the tinnitus field which may help overcome obstacles faced in the pharmacological treatment of tinnitus. These include incomplete knowledge of tinnitus pathophysiology, lack of well established animal models, heterogeneity of

Correspondence to: Berthold Langguth, Berthold. Langguth@medbo. de.

Declaration of interest: B Langguth is supported by the Deutsche Forschungsgesellschaft and the Tinnitus Research Initaitive; R Salvi is supported by grants from NIH (R01DC009091 and R01DC009219, RS) and Tinnitus Research Initiative; AB Elgoyhen is supported by the Tinnitus Research Initiative and a Howard Hughes International Scholar Grant. 
different forms of tinnitus, difficulties in tinnitus assessment and outcome measurement and variablility in clinical trial methodology.

\section{Keywords}

Auditory system; hearing; phantom perception; pain; inner ear; antidepressants; anticonvulsants; anxiolytics; GABA; NMDA; glutamate

\section{Background}

Tinnitus can be differentiated in two broad categories. 'Objective tinnitus'or 'somatosound' refers to the rare number of cases in which a sound source can be identified. Examples include abnormal blood flow pulsations in vessels adjacent to the middle ear or abnormal rhythmic muscle contractions as in palatal myoclonus (1). In contrast, 'subjective tinnitus', sometimes referred to as a 'phantom' auditory perception, refers to the much more common form in which the source of the auditory sensation cannot be identified. Henceforth, this condition will be referred to simply as 'tinnitus'. Tinnitus can take a variety of forms including tonal, hissing, ringing, whistling or 'cricket-like' sound. Tinnitus is prevalent in the general population, with approximately 10-15\% experiencing it in some form. Even if most people can learn to ignore the phantom sound, in about $1-3 \%$, tinnitus severely affects their quality of life $(2 ; 3)$. Thus, for approximately 13 million people in western Europe and the USA, tinnitus negatively affects their life to the extent that they seek medical advice and treatment (4). Although certain common trends are found across the patient population, tinnitus can have many different underlying causes. In particular, it often co-occurs with sensorineural hearing loss which might explain its increasing prevalence with age (3). However, tinnitus can be associated with virtually all disorders affecting the auditory system. Numerous studies report that the pitch of the tinnitus sensation matches the region of the hearing loss (5-7). These findings suggest that tinnitus arises in the central nervous system as a consequence of reduced auditory input from a partly deafferented cochlea. This resembles to some extent the pathophysiologic mechanisms involved in the generation of phantom pain after limb amputation. This notion is further supported by the observation that tinnitus persists even after transection of the auditory nerve (8). In addition, acute reduction of auditory input to very low levels leads to tinnitus-like phantom sounds $(9 ; 10)$. However, all those with hearing disorders perceive tinnitus. It has been recently shown that the risk of developing tinnitus depends on the exact slope of the audiogram. A steep slope of the audiogram might lead to abrupt discontinuities in the activity along the tonotopic axis with increased risk for the occurrence of tinnitus (7). Conversely, tinnitus can also occur in people with clinically normal hearing in the $250-8000 \mathrm{~Hz}$ range, although hearing loss cannot be ruled out by a normal audiogram, especially if it occurs between 8000-20,000 Hz. In a survey of over 2000 tinnitus patients, Henry et al (1) reported that prolonged noise exposure and noise trauma were an associating factor for the majority of cases $(22 \%)$, followed by head and neck injury (17\%), infections and neck illness (10\%) and drugs and other medical conditions $(13 \%)$. The remaining could not identify any specific known event associated with their tinnitus onset.

Tinnitus can be either a transient experience or a persistent chronic disorder. Similar to chronic pain, tinnitus is a purely subjective phenomenon and therefore extremely difficult to evaluate (11). Tinnitus assessment procedures often involve a description of its perceptual characteristics such as temporal duration, spatial lateralisation, loudness, pitch, masking characteristics and sensitivity to residual inhibition (12). In addition, the amount of distress, annoyance, and impact on daily living is important. Usually, the subjective tinnitus intensity is estimated by application of a visual analogue scale (VAS) or a numeric rating scale (NRS) for intensity. Objectively quantifying tinnitus is attempted by matching or masking methods. 
Matching is achieved by offering different tones to the patient and asking what frequency and intensity best fit their tinnitus. When matching the tinnitus to an external sound presented to the ear without tinnitus, the vast majority of the patients rate their tinnitus as less than 5-10 $\mathrm{dB}$ above hearing threshold expressed as $\mathrm{dB}$ sensation level (dB SL) (13). Masking, the estimation of the minimum noise level required to mask the tinnitus, has been shown to be more reliable for assessment of tinnitus loudness (14). However, it has to be taken into consideration that the tinnitus of some patients cannot be masked at all.

The handicap and the amount of distress that tinnitus evokes is assessed by validated self-report tinnitus questionnaires in the majority of studies (11). However, there is only a poor correlation between the intensity of the tinnitus as qualified by matching or masking techniques and the degree of annoyance the tinnitus creates (15). The poor correlation between tinnitus loudness and the perceived annoyance points to an important role of non-auditory factors such as emotion or attention $(16 ; 17)$.

Although the exact pathophysiological mechanisms underlying different forms of tinnitus are still not completely understood, there is growing evidence that changes in neuronal activity in different parts of the auditory pathway, including the dorsal cochlear nucleus, inferior colliculus, thalamus and/or auditory cortex underlie tinnitus pathology (18-25). A decrease in inhibition and/or increase in excitation may lead to an excitatory-inhibitory imbalance that can cause neural hyperexcitability in these regions leading to the perception of phantom sounds. Neuronal excitability can be modulated by different neurotransmitters and neuromodulators that act on voltage- or ligand-gated channels. So there is no reason to believe that the neural activity underlying tinnitus cannot be pharmacologically targeted. The fact that intravenous lidocaine, a local anesthetic that blocks voltage-gated sodium channels (26), can lead to the temporary reduction or total disappearance of tinnitus in $70 \%$ of patients (27) is a proof of principle.

\section{Medical need}

The greatest medical need arises from the 1 to $3 \%$ of the population that is severely affected by tinnitus, with major negative impact on quality of life (2). Severe tinnitus is frequently associated with depression, anxiety and insomnia $(28 ; 29)$. Moreover, tinnitus incidence is increasing dramatically with industrialization and longer lifespan. In developed countries the increase of leisure noise is expected to increase the incidence of hearing loss and tinnitus (4; $30 ; 31$ ). Tinnitus is a frequent work-related disability and the financial burdens it imposes on governments and industries are significant. The "US Veterans Administration Benefits Report" ranked tinnitus as the second most prevalent service related disability. Among those who began receiving benefits in 2006, tinnitus was ranked first among service related disability, accounting for $9.7 \%$ of the total (http://www.vba.va.gov/bln/21/). In 2006, the annual compensation for tinnitus related disability was $\$ 536$ million.

Despite the significant clinical need for effective treatment of tinnitus, there is currently no single FDA- or EMEA-approved drug on the market. A review of controlled clinical trials of tinnitus published in 1999 (32) concluded that no studied drug provides replicable, long-term reduction of tinnitus impact, in excess of placebo effects. Unfortunately, this has not changed during the last ten years (33).

For the majority of tinnitus sufferers that seek medical advice, the treatment goals are aimed at symptomatic relief, since causally oriented therapeutic strategies are lacking. The most frequently used therapies consist of auditory stimulation and cognitive behavioral treatment aimed at improving habituation and coping strategies. Importantly, over 4 million prescriptions are written each year in Europe and the US for tinnitus relief (34), but these are all off-label prescriptions from a wide variety of therapeutic drugs with uncertain efficacy. In addition, a 
large, undocumented group of tinnitus patient "self-medicate" with a plethora of nutriceutical compounds that do not require a prescription. Most clinicians who treat tinnitus patients would welcome an evidence-based effective drug therapy targeted at tinnitus. Thus, there is a pressing need to identify drugs that can provide significant tinnitus relief. Since in some individuals, tinnitus causes irritability, agitation, stress, depression, insomnia and interferes with normal life, even a drug that produces a small but significant effect would have a huge therapeutic impact. However, a drug that leads to the disappearance of tinnitus should be the ultimate goal.

\section{Existing treatments}

A large variety of pharmacological agents are used for the treatment of tinnitus (Table 1). Some, but not all of the drugs in Table 1 have been examined in clinical trials. However, there is considerable variability in the methodologic rigor of the different trials. Shortcomings in trial methodology include lack of placebo-controlled double-blind design, use of inadequate outcome measures, short duration of clinical trials, and lack of follow-up periods or large dropout rates. There is no drug which has been specifically developed to treat tinnitus. Some agents have been used to target symptoms frequently associated with tinnitus such as depression, anxiety or insomnia. Other substances have been investigated either based on pathophysiological hypotheses, on serendipitous clinical observations or due to their efficacy in clinical conditions that are thought to share pathophysiologic similarities with tinnitus, such as epilepsy (35) or central pain (36). It is worth mentioning that some of the pathophysiologic hypotheses, such as the putative involvement of cochlear vascularisation, are highly speculative. Thus, results from pharmacologic interventions may also be useful for either confirming or rejecting the hypotheses underlying their use.

It seems unlikely that there will be one single drug which will cure all forms of tinnitus. It is likely that many subtypes of tinnitus exist and that each will require a different form of treatment. Thus, one of the pressing needs in tinnitus research is a scheme to classify patients into subtypes that might respond positively to a specific drug treatment. Indeed, some drugs have been reported to provide moderate relief of symptoms in a subset of patients. Careful clinical observations along with data from clinical trials have provided useful clues for deciding on a rational course of drug therapy for selected patients. However, apart from intravenous lidocaine, which transiently suppresses tinnitus in a significant subgroup of patients (27), but which cannot be used for long-term treatment, no drug has been proven sufficient effectiveness in at least two randomized controlled clinical trials. The fact that positive results in some trials could not be replicated by following trials may be due to methodological shortcomings in many studies, such as the lack of proper control groups or small sample sizes. A further explanation for negative or dissimilar results across studies may be the pathophysiologic heterogeneity of tinnitus (37), highlighting the importance of subgrouping tinnitus according to the underlying pathophysiology. Drugs investigated to suppress tinnitus will be reviewed in the following sections in detail.

\subsection{Lidocaine}

Already in 1935, lidocaine was found to suppress tinnitus following nasal administration (38). Since then, many clinical studies have confirmed transient tinnitus suppression by intravenous administration in 40-70\% of tinnitus subjects (39-41). The effect seems to be dose dependent with suppression of tinnitus occurring at free arterial plasma concentrations from 1.75 to $3.5 \mu \mathrm{mol} / \mathrm{L}$, whereas concentrations above $3.5 \mu \mathrm{mol} / \mathrm{L}$ may induce tinnitus (42). The mechanisms of action by which intravenous lidocaine suppresses tinnitus are only incompletely understood, but there is evidence that it affects both the cochlea and the central nervous system $(22 ; 43 ; 44)$. A recent study has demonstrated, that lidocaine can suppress tinnitus even after transection of the auditory nerve (44). Lidocaine is generally used as a local anesthetic or to treat cardiac arrhythmias (45). The mode of action of lidocaine is complex. It binds to fast 
voltage-gated sodium channels, reducing the magnitude of the sodium current during depolarization (46-48). It also affects calcium, potassium, and glycine-evoked chloride currents (49). In human brain imaging studies in which lidocaine decreased the loudness of tinnitus, the changes in loudness were associated with altered neural activity in the right auditory association cortex $(22 ; 50)$. Since the effects of lidocaine are short lived and due to its potentially life threatening arrythmogenic side effects, lidocaine is not an option for long-term treatment. Oral analogues of lidocaine such as tocainide have been evaluated as a potential long-term therapy for tinnitus. However, several randomized, controlled studies found that tocainide had little benefit for tinnitus (51-53), so it has been assumed that the tinnitus suppressing action of lidocaine is not due to the sodium channel blocking activity common to these two drugs.

\subsection{Benzodiazepines}

Several benzodiazepines have been tested for the treatment of tinnitus. Benzodiazepines bind to the benzodiazepine site of the $\mathrm{GABA}_{\mathrm{A}}$ receptor where they act as allosteric modulators, potentiating the action of GABA and thus increasing the permeability of chloride ions leading to hyperpolarization and decreased excitability (54). The different benzodiazepines differ in their half-life and are used as sedatives, anxiolytics, anticonvulsants and muscle relaxants. Alprazolam, a short-acting triazolobenzodiazepine has been investigated for tinnitus treatment in a prospective, double blind placebo controlled study (57). Alprazolam reduced tinnitus loudness in $65 \%$ of subjects compared to $5 \%$ in the control group. Even if these results seem encouraging, caution in the interpretation of these data is warranted because of the lack of assessment of emotional aspects, the small sample size of 40 patients and the lack of replication (32). Diazepam, a longer acting benzodiazepine was evaluated in a pilot trial involving 21 tinnitus patients (58). In contrast to alprazolam, which has a very similar mechanism of action, diazepam had no effect on tinnitus loudness. One possible explanation for the discrepancy was that the dose of alprazolam, but not diazepam, was adjusted for each patient to maximize its effects on tinnitus (57).

Further data is available from a large retrospective study of clonazepam, a long acting benzodiazepine. Medical records from over 3000 patients taking clonazepam $(0.5-1 \mathrm{mg} / \mathrm{day}$, 60-180 days) for vestibular or cochleovestibular disorders revealed improvement of tinnitus in $32 \%$ (59). In a prospective, randomized, single-blind clinical trial involving 10 patients per group, clonazepam significantly reduced tinnitus loudness and annoyance relative to the control group (60), however replication is needed because of the small sample size and the lack of double blinding. Clinical use of benzodiazepine is limited by their side effects such as high risk of drug dependency and personality changes. Moreover, caution is warranted since protracted tinnitus has been reported after discontinuation of benzodiazepines $(55 ; 56)$.

\subsection{Antidepressants}

The tricyclic antidepressants nortriptyline, amitriptyline and trimipramine have been investigated for the treatment of tinnitus. Beside their antidepressant properties, tricyclics have been shown to be highly efficient for the treatment of chronic pain, which is of interest in view of the proposed etiological similarities between tinnitus and neuropathic pain $(36 ; 61)$. Amitriptyline inhibits the reuptake of serotonin and noradrenaline almost equally, whereas nortriptyline inhibits mainly the reuptake of norepinephrine and to a lesser extent serotonin. Trimipramine differs in its mode of action from other tricyclic antidepressants in that it blocks postsynaptic dopamine and serotonin receptors (62).

One study compared amitriptyline with placebo and found that 6 weeks with amitriptyline at $100 \mathrm{mg}$ per day significantly reduced tinnitus complaints and tinnitus loudness compared to the placebo group (63). In another study, where amitriptyline was compared with biofeedback, 
$27.5 \%$ of patients reported improvement with amitriptyline while $43.5 \%$ reported improvement with biofeedback revealing the superiority of biofeedback (64). In a small scale, single-blind, placebo-washout study involving patients with severe tinnitus and major depression, nortriptyline significantly reduced depression, and tinnitus loudness (10 dB reduction) (65). These positive results in tinnitus patients with depression were confirmed in a double-blind placebo-controlled follow up study (66). There was a significant correlation between the reduction in tinnitus disability scores and depression scores (67) suggesting that positive effects on tinnitus may mainly be a consequence of nortriptyline's antidepressant effect. Trimipramine was evaluated in a small double blind, placebo crossover study (68), which did not demonstrate a difference between trimipramine and placebo treatment. Interestingly, tricyclic antidepressants have also been repeatedly found to induce tinnitus (69-71). Serotonin reuptake inhibitors have also been investigated for the treatment of tinnitus. Paroxetine was investigated in a double-blind, placebo-controlled study involving chronic tinnitus patients without comorbid depression. In this study paroxetine was not superior to placebo in its effect on tinnitus loudness and Tinnitus Handicap Questionnaire scores (72). Sertraline, a serotonin reuptake inhibitor, which also inhibits the dopamine transporter, has been studied in a randomized, double-blind placebo-controlled trial of patients with comorbid depression and anxiety. Sertraline was found to be more effective than placebo in reducing tinnitus loudness and Tinnitus Severity, but not tinnitus annoyance (73). Collectively, the results suggest that tinnitus patients with depression and anxiety may benefit from antidepressants (74). However, this effect may not to be a direct effect of antidepressants on tinnitus severity, but rather due to the beneficial effect of antidepressants on comorbid depression and anxiety.

\subsection{Anticonvulsants}

The anticonvulsant carbamazepine which binds to voltage-gated sodium channels and stabilizes the sodium inactivation state, thereby reducing neural firing $(75 ; 76)$, has been investigated for tinnitus with mixed results. Based on the assumption that carbamazepine resembles lidocaine in its mechanisms of action, three studies investigated the effect of carbamazepine in tinnitus patients who previously had responded to intravenous lidocaine $(41 ; 77 ; 78)$. About half of these patients had a positive response to carbamazepine (600-1000 $\mathrm{mg}$ daily). On the other hand, several randomized clinical trials reported no beneficial effect of carbamazepine on tinnitus, which may be due to the low dosages ( $200 \mathrm{mg} /$ day) used in these studies (79-81). A rare group of patients that receives significant benefit from carbamazepine are those who have intermittent tinnitus that is caused by vascular compression of the auditory nerve and which is characterized by sounds like a typewriter, pop corn or ear clicking (82; 83). In rats, carbamazepine was found to suppress salicylate induced tinnitus at a dosage of 15 $\mathrm{mg} / \mathrm{kg}$, but not by lower or higher doses (84).

The anticonvulsant gabapentin, which acts on voltage-gated calcium channels, is used for the treatment of neuropathic pain and migraine. Pilot studies $(85 ; 86)$ and an animal study $(87)$ have suggested positive effects. However, several large, randomized clinical trails failed to demonstrate benefit of gabapentin over placebo in treating tinnitus (88-91). Vigabatrin and tiagabine, two anticonvulsants that act on different aspects of GABAergic neurotransmission have been studied in noise-exposed rats with behavioral evidence of tinnitus. Whereas tiagabine had no effect, vigabatrin suppressed noise-induced tinnitus and tinnitus reappeared when vigabatrin treatment was stopped (92). Unfortunately, vigabatrin can cause irreversible visual field deficits in some patients, therefore the practical use of vigabatrin in humans is very restricted (93).

\subsection{Antiglutamatergic agents}

Excitotoxicity mediated by NMDA receptors has been proposed as a mechanism for cochlear tinnitus (94-96). Moreover, an imbalance between inhibitory versus excitatory 
neurotransmission has been observed in several regions of the auditory pathway in tinnitus (19). High doses of salicylate reliably induce tinnitus and augment currents through NMDA receptors on cochlear spiral ganglion neurons $(97 ; 98)$. NMDA antagonists applied locally to the inner ear blocked behavioral evidence of salicylate-induced tinnitus (95). Cochlear application of a selective NMDA antagonist in the first four days following noise exposure also reduced the probability of developing noise-induced tinnitus (96).

Caroverine, a spasmolytic drug, which is an antagonist of non-NMDA and NMDA glutamate receptors (99), has been investigated in patients with putative cochlear tinnitus. Patients were randomized to receive either caroverine (i.v., maximum dose $160 \mathrm{mg}$ ) or placebo. Within the caroverine group, $63 \%$ showed a reduction in loudness immediately after treatment and $43 \%$ still showed improvement one week later, whereas there was no improvement in the placebo group (100). However these encouraging results could not be replicated by a subsequent study that followed the same protocol (101).

Memantine, which is approved for the treatment of Alzheimer's disease, is a voltage-dependent antagonist of NMDA receptors and reduces excitotoxicity by reducing calcium influx (102). In addition, it blocks serotonin and nicotinic acetylcholine receptors $(103 ; 104)$. In contrast to the positive results seen with cochlear application of NMDA antagonists, systemic memantine failed to reduce tinnitus both in an animal study (105) and in a relatively large human prospective, randomized, double-blind crossover study (106). Flupirtine, an NMDA antagonist with analgesic properties has been investigated in a small open trial where it did not show any beneficial effect (107).

Acamprosate influences the balance between GABAergic and glutamatergic transmission by blocking NMDA receptors and enhancing GABAergic transmission (108). It is approved for the treatment of alcoholism. With the rationale that reduced GABAergic inhibition and increased glutamatergic excitation in the auditory pathways are involved in tinnitus generation, the efficacy of acamprosate has been investigated. In a double-blind placebo-controlled study, in which most patients suffered from noise-induced hearing loss, acamprosate $(333 \mathrm{mg}, 3$ times per day) resulted in a significant reduction of tinnitus loudness after 90 days of treatment (109). A larger clinical trial has been initiated to assess the encouraging results from this preliminary study (http://clinicaltrials.gov/ct2/show/NCT00596531).

\subsection{Dopaminergic/antidopaminergic agents}

Both dopaminergic and antidopaminergic drugs have been proposed for treating tinnitus. On the one hand dopamine is an inhibitory transmitter in the cochlea; on the other hand antidopaminergic drugs improve thalamic filtering of sensory signals. Furthermore, dopaminergic pathways in limbic and prefrontal areas may be involved in mediating emotional aspects of tinnitus (110-112). Sulpiride, an antipsychotic drug that selectively blocks dopamine D2 receptors (113) significantly reduced subjective ratings of tinnitus and tinnitus visual analogue scores in one double-blind, placebo-controlled study. However, the reductions with sulpiride were not significantly lower than those in the placebo group. Two further studies investigated combinations of sulpiride with melatonin or with hydroxyzine. Both combinations were significantly more effective in reducing tinnitus visual analogue scale and tinnitus perception scores than placebo $(114 ; 115)$. The dopamine agonist piribedil was evaluated in a 515 elderly patients; $20 \%$ were reported to show complete resolution of memory impairment, vertigo and tinnitus while $73 \%$ showed improvement. (116). While these results are encouraging the lack of controls leave many questions unanswered. Piribedil was investigated recently in a double-blind placebo-controlled cross-over study. Results showed that piribedil was not superior to placebo, however a post-hoc analysis suggested that a subgroup of patients with specific findings in electrocochleography may benefit from piribedil (117). 


\subsection{Other Compounds}

A large variety of drugs from different pharmacological classes is currently prescribed for tinnitus (see Table 1), in spite of the fact that for a large number of them no data from clinical trials is available. Here we will review only those compounds, for which clinical studies have been performed.

Systemic and intratympanic steroids have been proposed for the treatment of acute tinnitus, especially if it is related to sudden onset of hearing loss (118-120). Although some studies report positive results in subset of patients, the value of steroids in the treatment of idiopathic sudden sensorineural hearing loss remains unclear since the evidence from randomized controlled trials are contradictory in outcome (121).

Ginkgo biloba contains bioactive flavonoids and terpenes with vasoactive and antioxidant properties and has been proposed for the treatment of a wide range of disorders including tinnitus (122). Even though some studies have suggested beneficial effects of gingko on tinnitus, particularly in patients with short duration symptoms $(123 ; 124)$, there is a growing body of evidence from large, well controlled, double-blind, placebo-controlled clinical studies clearly indicating that gingko is no more effective in alleviating tinnitus symptoms than placebo (125-127).

Melatonin, a naturally occurring circulating hormone, binds to melatonin receptors and plays an important role in regulating circadian rhythms $(128 ; 129)$. Melatonin is also a potent antioxidant that protects mitochondrial and nuclear DNA (130) and has been suggested to protect against noise- and drug-induced hearing loss $(131 ; 132)$. Since sleep disturbances represent a major complaint and complicating factor in tinnitus, melatonin was evaluated as a treatment for tinnitus in three studies. An open label study found statistically significant improvements on ratings of tinnitus severity and sleep quality (133), whereas a double-blind, placebo-controlled cross over study did not demonstrate superiority of melatonin over placebo (134). A more recent, randomized, placebo-controlled double-blind study found that melatonin in combination with sulpiride reduced subjective ratings of tinnitus and tinnitus loudness more than placebo (114).

Zinc, an essential trace metal plays an important role in numerous biological signaling functions and is widely distributed in the auditory pathway $(135 ; 136)$. While positive results have been reported in some patients with hypozincemia, zinc therapy did not result in tinnitus improvement in patients with normal zinc levels in several double-blind, placebo-controlled studies (137-140).

Misoprostol is a synthetic prostaglandin E1 analogue which is primarily used to prevent gastric ulcers induced by non-steroidal anti-inflammatory drugs (141). In a small, placebo-controlled cross-over study, tinnitus severity improved in $33 \%$ of subjects during misoprostol treatment (dose escalating to $800 \mu \mathrm{g} / \mathrm{day}$ ), while none improved with placebo (142). Two subsequent double-blind placebo-controlled studies have shown a significant reduction of tinnitus loudness with misoprostol treatment, but no differences in subjective measures of tinnitus severity (143).

Atorvastatin reduces the synthesis of cholesterol by inhibiting HMG-CoA reductase and is used to lower blood cholesterol and prevent vascular events (144). In a randomized, doubleblind placebo-controlled study over 13 months involving elderly patients with elevated cholesterol, atorvastatin failed to slow the progression of age-related hearing loss or to significantly reduce tinnitus (145). 
Nimodipine, a calcium antagonist, which crosses the blood-brain barrier and blocks L-type calcium channels (146) is primarily used in the treatment of subarachnoid hemorrhage (147). Pilot studies also suggest beneficial effects in mood disorders (148). In animal studies nimodipine significantly reduced tinnitus related behavior caused by high doses of quinine or sodium salicylate (149). The first open clinical trial suggested positive effects of nimodipine on tinnitus in some patients (150). However, these results could not be confirmed in a second open clinical trial (151).

Furosemide is a loop inhibiting diuretic used to treat congestive heart failure and edema (152). Furosemide inhibits the Na-K-2Cl cotransporter (153), which is expressed in the inner ear as well as in the brain $(154 ; 155)$. Furosemide has been proposed as a treatment for tinnitus of cochlear origin because it strongly suppresses the endolymphatic potential and other cochlear responses (156). In one study, approximately 50\% of patients reported a reduction of tinnitus symptoms following intravenous furosemide treatment. Furosemide has also been found to suppress tinnitus in approximately $40 \%$ of patients with Meniere's disease (157). In contrast to these positive findings, high doses of furosemide have also been found to induce temporary hearing loss and tinnitus $(158 ; 159)$.

Osmotic drugs such as mannitol or glycerol have been investigated in tinnitus. However, in an open trial tinnitus was only relieved in $13.1 \%$ of patients treated with glycerol and $5.8 \%$ of those treated with mannitol (160).

Scopolamine, which acts as a competitive antagonist of M1 muscarinic acetylcholine receptors, is used to treat motion sickness, nausea and intestinal cramps $(161 ; 162)$. In an animal study, high doses of salicylate, which induces tinnitus, increased the expression of c-fos and arg3.1 in the auditory cortex suggesting that they were biomarkers of tinnitus. Administration of scopolamine suppressed the expression of c-fos and arg3.1 in the auditory cortex suggesting that scopolamine might be a treatment for tinnitus (163). However, when behavioral measures of tinnitus were obtained from rats, scopolamine failed to suppress behavioral evidence of salicylate-induced tinnitus (164).

Cyclandelate, a vasodilator that is believed to act by blocking calcium influx (165), has been investigated for the treatment of tinnitus based on the assumption, that some forms of tinnitus may arise from cerebrovascular insufficiency. In an open, multi-centric clinical trial of patients with tinnitus, vertigo and visual disturbances, 90-day treatment with cyclandelate reduced the severity and frequency of these symptoms with minimal side effects (166). However, in a subsequent placebo-controlled, double-blind study cyclandelate did not significantly change audiometric measures of tinnitus loudness and pitch and caused side effects in many patients (167).

Botulinum toxin has been investigated in a small pilot study, where it has demonstrated superiority over placebo (168). Botulinum toxin has also been shown to be highly effective in the rare cases where tinnitus is caused by palatal tremor (169).

\section{Market review}

Although there are no FDA or EMEA approved drugs to treat tinnitus, a potential market for such drugs is just beginning to emerge. No published market research data on the use of drugs to treat tinnitus could be located. Some relevant market data are available from a "Tinnitus Market Situation Analysis", which was prepared by the Royal National Institute of Deafness in 2003 (34). Data about drug prescriptions related to tinnitus (as provided by IMS Health and only reflecting drugs prescribed in primary care) illustrate the variation in prescribing habits between different countries, which reflects the lack of availability of an effective treatment. Based on epidemiologic data, customer research and market data of some products used for 
tinnitus management, the Royal National Institute of Deafness estimated the patient opportunity for a tinnitus drug would be 8.2 million in 2003 and increasing to 15 million by 2012. The market value of Tinnitus Retraining Therapy and off-label pharmaceuticals was estimated in 2003 to be 127 million US \$. The market value of the whole segment "symptomatic relief from tinnitus" was estimated to be 1.1 billion US \$, with a huge potential to increase if an effective drug for the relief of tinnitus was to become available. This can be explained by the large number of people with tinnitus who have stopped seeking medical treatment because of the lack of effect treatment option, but who would likely be interested in treatment as soon as an effective compound is be available (34).

\section{Current research goals}

There is widespread recognition that consistency between research centers in the ways that patients with tinnitus are assessed and how interventions outcomes are measured would facilitate more effective cooperation and more meaningful evaluations of tinnitus treatments (11).

Advances in neuroimaging are expected to contribute to better characterization of the neuronal correlate of tinnitus and to the identification of new targets for treatment (170). A further potential application is the differentiation between different forms of tinnitus. It is assumed, that differences in the perceptual characteristics of tinnitus, in the emotions surrounding tinnitus, and in the response to specific treatments are reflected by specific patterns of neural activity, which could be detected by the use of imaging techniques. By contributing to differential diagnosis, imaging may also serve as a predictor for specific treatments. Furthermore, neuroimaging can be used for the assessment of the neuronal mechanisms by which specific treatments exert their effects. This knowledge, in turn, can be useful for improving efficacy of those treatment interventions.

One major limitation to the development of drugs to treat tinnitus and its associated emotional symptoms has been the lack of in vitro bioassays or validated animal models in which to test or screen for compounds. Several animal models have been developed which are based on induction of tinnitus-like behaviors with noise exposure or on the administration of salicylate $(87 ; 97 ; 164 ; 171)$. However, it remains to be determined to what extent data from drug trials in the available animal models can be extrapolated to efficacy in humans.

\section{Scientific rationale}

There is compelling evidence, that tinnitus is related to alterations of neural activity in the central nervous system. These alterations are most probably due to altered sensory input, e.g. by cochlear pathologies. However, most treatment approaches used in the past, such as vasodilatators or free radical scavengers were given under the assumption that tinnitus is generated in the cochlea. Even among those drugs which are currently under development for tinnitus (see next section and table 2), the cochlea is still the main target. This is even more astonishing since the observed changes in neural function, such as increased firing rate or increased synchrony should represent easier targets for pharmacological interventions than hair cell damage in the cochlea. Why is this cochlear approach so persistently followed if it has not been proven successful in the past, especially since there has been strong evidence for tinnitusrelated changes in the brain for more than a decade now (172;173)? One explanation may be that some of the drugs under development mainly aim to prevent hearing loss or to treat it at early stages. For this purpose the cochlea is probably the most promising target and successful pharmacologic treatment of acute hearing loss has probably also beneficial effects on accompanying tinnitus. 
Another explanation may be the fact that the most widely used animal model for tinnitus is salicylate induced tinnitus. Since it has been assumed for years that salicylate produces tinnitus by interfering with neural transmission in the cochlea $(95 ; 96)$, pharmacologic interventions in animals were primarily targeting the cochlea. Only recently it has been shown, that salicylate, in addition to its effects on the cochlea, increases the gain in central auditory pathways (174). This finding may contribute to move the focus of attention for pharmacologic treatment of tinnitus further to the central nervous system. Tinnitus related changes of central nervous system activity are regulated by a variety of neurotransmitters such as GABA, glutamate or serotonin, which can be modulated by pharmacologic treatment. Relatively strong, but only transient effects on tinnitus have been reported after intraveneous lidocaine. Some antidepressants and anticonvulsants seem to have moderate effects in subgroups of tinnitus patients. So there are some hints indicating that activity-driven changes underlying tinnitus can be pharmacologically targeted.

An important step towards designing a successful strategy in the search for tinnitus drugs should include criteria to stratify or classify tinnitus patients included in trials. As previously discussed, tinnitus often occurs as a result of insults to the ear, such as from noise exposure or from administration of specific pharmacologic agents. It can also be caused by ear or head injuries, some diseases of the ear and ear infections $(19 ; 175)$. In some cases the causative agent remains unknown. The identification of the triggering cause may be of importance for selecting the most adequate pharmacological approaches. Moreover, the manifestation of tinnitus can vary, ranging from intermittent tinnitus perception with little impact on daily life to a devastating roar that occurs 24 hours a day preventing sleep, the ability to do intellectual work, leading to social isolation. Tinnitus is also often associated with other symptoms, such as hyperacusis and distortion of sounds (175). Affective disorders, such as anxiety, phonophobia and depression, often accompany severe tinnitus and that form of tinnitus can lead to suicide. With such differences in etiology and symptoms, heterogeneity within tinnitus patients is expected. Specific pathophysiological mechanisms have already been identified for specific clinical factors such as the perceived localization $(21 ; 24)$, the duration $(25 ; 176)$ or the frequency composition (177). Differential diagnosis of triggering events and temporal onset should allow for a more rational and efficacious pharmacological approach. The fact that a subgroup of patients who have intermittent tinnitus that sounds like a typewriter, pop corn or ear clicking receive significant benefit from carbamazepine (82;83), indicates that "subtyping" tinnitus is highly recommended. Efforts towards establishing subgroups of tinnitus are under way $(11 ; 178 ; 179)$, and will most likely aid the post-hoc identification of responders to specific drugs and the selection of patients in future clinical trials.

Another strategy to address the lack of 'good fortune' in drug discovery may be systematic study of normal auditory physiology. Pharmacologic modulation of auditory signal processing may yield useful clues as to the action of putative drugs for tinnitus treatment.

Advances in the understanding of tinnitus pathophysiology reveal a large number of similarities with other disorders of the central nervous system, such as chronic pain, epilepsy, posttraumatic stress disorder or affective disorders, suggesting that pharmacologic targets for the treatment of these disorders may also represent promising candidates for treating tinnitus. Thus, for a new compound, which is under development for any of these conditions, additional testing for tinnitus may be warranted.

\section{Competitive environment}

There are only a small number of drugs in development for the treatment of tinnitus. However, tinnitus can be found attached to long lists of indications in many more patents filed on molecules aimed at a range of diverse therapeutic classes. A search carried out in the 
investigational drugs databases Pharmaprojects (www.pharmaprojects.com), AdisInsight (www.adisinsight.com), Prous DDR (www.prous.com) and IDdb3 (http://science.thomsonreuters.com), shows that only a small number of compounds is currently developed for tinnitus (Table 2). Neramexane acts as a non-competitive, voltagedependent NMDA antagonist and also blocks $\alpha 9 \alpha 10$ nicotinic cholinergic receptors which are expressed on hair cells in the inner ear (180-182). After obtaining positive results from a Phase II trial (http://clinicaltrials.gov/ct2/show/NCT00405886), Merz Pharmaceuticals is currently conducting Phase III multi-center clinical trials to determine the efficacy, safety and tolerability of Neramexane for treating tinnitus (http://clinicaltrials.gov/ct2/show/NCT00739635, http://clinicaltrials.gov/ct2/show/NCT00772980, http://clinicaltrials.gov/ct2/show/NCT00827008).

LidoPAIN TV is a non-sterile patch delivering lidocaine, which is applied to the periauricular skin region. According to the company's web page, it demonstrated efficacy in a clinical proofof-concept study and has been in phase II trials for tinnitus.

The orally active drug SPI- 1005 contains ebselen which acts as an antioxidant by stimulating glutathione peroxidase. It has completed a phase I trial and phase II trials are planned for the treatment of noise-induced hearing loss and tinnitus.

AM 101 is an NMDA antagonist, which is applied topically to the cochlea by round window injection for the treatment of acute tinnitus. In a randomized, double-blind placebo-controlled German Phase I/II trial in 24 patients with acute tinnitus following noise trauma or sudden deafness, single-dose AM-101 intratympanic injection was well tolerated. It also had a positive effect on tinnitus loudness and showed a trend in the tinnitus handicap as measured with the TBF-12 questionnaire. Currently a double-blind, randomized, placebo-controlled Phase II trial with cochlear application of AM-101 is being carried out. The study involves patients with acute ( $<3$ months) noise-induced tinnitus that have not responded to glucocorticoid treatment (http://clinicaltrials.gov/ct2/show/NCT00860808). The same company has also a second compound under development (AM-102). This compound is of unidentified pharmacologic activity and is also delivered by intratympanic application. It is currently in preclinical tests.

Vestipitant is a novel antagonist of the neurokinin-1 (NK-1) receptor which binds substance P. Neurokinin receptors are present in the inner ear and therefore represent a potential therapeutic target for tinnitus (183). Vestipitant and the combination of vestipitant and paroxetine are currently undergoing a phase II clinical trial for the treatment of tinnitus (http://clinicaltrials.gov/ct2/show/NCT00394056).

EGb-761 is a concentrated extract of Ginkgo biloba, enriched in flavonoids and terpenes, which has a broad spectrum of pharmacologic actions, including a free-radical scavenger effect and which has shown efficacy for tinnitus in a phase I trial.

\section{Potential development issues}

Why is the number of companies with tinnitus compounds in their pipelines so limited in spite of the existence of such a huge market for a clinically unmet need? One reason is probably that the lack of serendipitous discoveries of effective treatments has severely limited insight into tinnitus pathology. An additional challenge in the design of drugs for the treatment of tinnitus derives from the fact that the neural substrates underlying tinnitus are far from being fully understood. Increase in spontaneous firing rates or neuronal synchrony in different parts of the auditory pathway as well as changes in cortical tonotopy have been proposed as potentials correlates of tinnitus (19;35). Modern drug discovery is mainly focusing on the identification of new chemical entities that interact with discrete molecular targets. This reductionist approach requires the knowledge of defined sites of drug action with known clinical relevance. 
Thus, it is the absence of a fully-determined neuronal correlate/s for tinnitus that makes research into this area potentially very high-risk. However even if a well-defined neuronal target would ease the path towards drug discovery, the empirical approach that has been used for most central nervous system disorders should not be precluded in the case of tinnitus. Most innovative central nervous system acting drugs were discovered serendipitously (184). Before a compound is judged suitable for testing in humans, it must first demonstrate safety and efficacy in animal models. A drawback in the development of a tinnitus drug is the lack of in vitro bioassays or validated animal models in which to test or screen for compounds. The basic dilemma faced by the animal researcher who wants to study tinnitus is whether or not the animals have tinnitus $(87 ; 97)$. An additional challenge is imposed by the fact that, in humans, tinnitus is accompanied by the activation of a distress network that involves the limbic system $(25 ; 185)$, which is probably not recapitulated in the animal models. Different animal models have been developed and validated for acute tinnitus perception $(97 ; 164 ; 171 ; 186 ; 187)$. However, it is questionable to which extent results from the currently available animal models can predict effectiveness of a drug on severity of chronic tinnitus in humans. Thus, there is a clear need for developing animal models of chronic tinnitus which also include detection of the extent of tinnitus-evoked emotional or cognitive changes. On the other hand, even in diseases where there is a greater mechanistic understanding, there are still significant disparities between the animal models used in discovery validation and the human diseases being targeted for treatment (188). Also, if we look at animal models that have been developed for even more complex central nervous diseases such as depression or schizophrenia, they have proven useful, even if they can serve only as models of disease mechanisms but not of the disease itself. Thus, the search for drugs to treat tinnitus should not wait for a complete understanding of the neural correlates of tinnitus nor the refinement of the animal models. Finally, because the first tinnitus drugs are yet to be approved, regulatory agencies such as the Food and Drug Administration (FDA) or the European Medicines Agency (EMEA), lack standardized protocols for their approval process. Therefore, the first pharmaceutical industry to develop a tinnitus drug will have to pave the way. This will be most successful as a collaborative effort with tinnitus researchers providing informed direction to drug companies and developing better lines of communication.

In addition, tinnitus being a subjective phenomenon, assessment of outcome is probably the single most important factor in conducting a clinical trial. Thus, definition of outcome measurements is not trivial, but probably critical for the design of clinical trial. A comprehensive evaluation includes the assessment of (1) tinnitus loudness, either by visual analogue scales or by psychoacoustic measurements and (2) of tinnitus severity, which is usually assessed by validated questionnaires. However since psychoacoustic measures of tinnitus loudness have shown only limited test- retest reliability (12) and only a low correlation with perceived tinnitus severity or annoyance $(189 ; 190)$ there is increasing consensus among clinical researchers, that psychoacoustic tests are only of limited value for outcome measurement (11). On the other hand it has been argued, that treatment interventions that aim to reduce tinnitus loudness, should not only be assessed by questionnaires of tinnitus annoyance but also by loudness measurements (179). Furthermore, it has to be considered that questionnaires for assessment of tinnitus severity have not been designed and validated for evaluating treatment induced changes. Thus, it is not clear to which extent these questionnaires are sensitive to treatment induced changes, especially since answer options in different questionnaires vary between 3-point ordinal scales $(191 ; 192)$ and 0-100 interval scales (193). Moreover most of the questionnaires have been validated by using the Beck Depression Inventory (BDI) and therefore their scores correlate highly with the BDI scores (29). Hence, in a sample of tinnitus patients with comorbid depression, a drug that has an antidepressant effect, but no effect on tinnitus would probably result in reduced tinnitus scores, just by reducing depressive symptoms. 


\section{Expert opinion}

Currently no drug is available that has demonstrated replicable, long-term reduction of tinnitus impact in excess of placebo effects. However, there is an urgent need for efficacious compounds and there is no reason to believe, that tinnitus cannot be effectively treated by pharmacotherapy. The development of behavioral measures of tinnitus in animals, together with molecular, biochemical, physiological, and imaging techniques are offering increasing insights into the underlying causes of tinnitus and to identify new potential targets for treatment. Moreover, animal models will provide a way to screen for new compounds that can suppress tinnitus. Imaging in combination with detailed standardized assessment will help to identify specific tinnitus subtypes that respond to specific treatments. Also efforts have been made to find consensus about patient assessment and outcome measures (11). These important advances in tinnitus research during the last years clearly indicate that those difficulties which currently hamper the search for effective pharmacologic treatment are solvable in the near future. The market for a tinnitus drug is already huge, untapped and likely to grow. Thus, looking towards a promising future, patients and clinicians may finally receive encouraging news if more and more compounds will be tested for tinnitus and if any of the compounds under development will reach the market. The availablility of an approved drug will enlarge therapeutical possibilities. It is also possible that the therapeutic value of certain drugs may be enhanced if used in combination with masker/sound therapy together with cognitive behavioural therapy. A major turning point or water shed event in the treatment of tinnitus, likely to occur in the next few years, is the FDA or EMEA approval of a drug to treat tinnitus and its debilitating side effects.

\section{Reference List}

1. Henry JA, Dennis KC, Schechter MA. General review of tinnitus: prevalence, mechanisms, effects, and management. J Speech Lang Hear Res 2005 Oct;48(5):1204-35. [PubMed: 16411806]

2. Axelsson A, Ringdahl A. Tinnitus--a study of its prevalence and characteristics. Br J Audiol 1989 Feb; 23(1):53-62. [PubMed: 2784987]

3 *. Hoffman, HJ.; Reed, GW. Epidemiology of Tinnitus. In: Snow, JB., editor. Tinnitus: Theory and Management. London: BC Decker; 2004. p. 16-41.a very comprehensive review over the epidemiology of tinnitus

4. Vio MM, Holme RH. Hearing loss and tinnitus: 250 million people and a US $\$ 10$ billion potential market. Drug Discov Today 2005 Oct 1;10(19):1263-5. [PubMed: 16214667]

5 *. Norena A, Micheyl C, Chery-Croze S, Collet L. Psychoacoustic characterization of the tinnitus spectrum: implications for the underlying mechanisms of tinnitus. Audiol Neurootol 2002 Nov;7 (6):358-69. this study has demonstrated, that the frequency of the tinnitus is similar to the frequency of hearing loss. [PubMed: 12401967]

6. Roberts LE, Moffat G, Bosnyak DJ. Residual inhibition functions in relation to tinnitus spectra and auditory threshold shift. Acta Otolaryngol Suppl 2006 Dec;(556):27-33. [PubMed: 17114139]

7 *. Konig O, Schaette R, Kempter R, Gross M. Course of hearing loss and occurrence of tinnitus. Hear Res 2006 Nov;221(1-2):59-64. here it was demonstrated that the slope of the audiogram determines the irsk for developing tinnitus. [PubMed: 16962270]

8. House JW, Brackmann DE. Tinnitus: surgical treatment. Ciba Found Symp 1981;85:204-16. [PubMed: 6915835]

9 **. HELLER MF, BERGMAN M. Tinnitus aurium in normally hearing persons. Ann Otol Rhinol Laryngol 1953 Mar;62(1):73-83. a classical study, which has shown, that normal hearing people perceive tinnitus-like phantom sensations, when they are deprived from environmental sounds. [PubMed: 13041055]

10. Del Bo L, Forti S, Ambrosetti U, Costanzo S, Mauro D, Ugazio G, et al. Tinnitus aurium in persons with normal hearing: 55 years later. Otolaryngol Head Neck Surg 2008 Sep;139(3):391-4. [PubMed: 18722219] 
11 **. Langguth B, Goodey R, Azevedo A, Bjorne A, Cacace A, Crocetti A, et al. Consensus for tinnitus patient assessment and treatment outcome measurement: Tinnitus Research Initiative meeting, Regensburg, July 2006. Prog Brain Res 2007;166:525-36. results of a consensus meeting on assessment of tinnitus patients and outcome measurements in clinical trials. [PubMed: 17956816]

12. Henry JA, Meikle MB. Psychoacoustic measures of tinnitus. J Am Acad Audiol 2000;11:138-55. [PubMed: 10755810]

13. Vernon JA, Meikle MB. Tinnitus: clinical measurement. Otolaryngol Clin North Am 2003 Apr;36 (2):293-305. vi. [PubMed: 12856298]

14 *. Tyler RS, Oleson J, Noble W, Coelho C, Ji H. Clinical trials for tinnitus: study populations, designs, measurement variables, and data analysis. Prog Brain Res 2007;166:499-509. a recent critical review of clinical trial design in tinnitus. [PubMed: 17956814]

15. Hiller W, Goebel G. Factors influencing tinnitus loudness and annoyance. Arch Otolaryngol Head Neck Surg 2006 Dec;132(12):1323-30. [PubMed: 17178943]

16 **. Jastreboff PJ. Phantom auditory perception (tinnitus): mechanisms of generation and perception. Neurosci Res 1990;8:221-54. in this "classical" paper a neurophysiological model of tinnitus has been presented, which has been later confirmed in many aspects. An essential part of this model is, that different neuronal mechanisms account for perception and annoyance of tinnitus. [PubMed: 2175858]

17 *. Moller AR. Pathophysiology of tinnitus. Otolaryngol Clin North Am 2003;36:249-66. a well written review about the pathophysiological mechanisms underlying tinnitus. [PubMed: 12856295]

18. Bauer CA, Turner JG, Caspary DM, Myers KS, Brozoski TJ. Tinnitus and inferior colliculus activity in chinchillas related to three distinct patterns of cochlear trauma. J Neurosci Res 2008 Aug 15;86 (11):2564-78. [PubMed: 18438941]

19 **. Eggermont JJ. Pathophysiology of tinnitus. Prog Brain Res 2007;166:19-35. an excellent summary of current knowledge about the neural correlates of tinnitus. [PubMed: 17956768]

20 *. Kaltenbach JA. The dorsal cochlear nucleus as a contributor to tinnitus: mechanisms underlying the induction of hyperactivity. Prog Brain Res 2007;166:89-106. an excellent summary of the role of the dorsal cochlear nucleus in tinnitus. [PubMed: 17956775]

21 *. Melcher JR, Sigalovsky IS, Guinan JJ Jr, Levine RA. Lateralized tinnitus studied with functional magnetic resonance imaging: abnormal inferior colliculus activation. J Neurophysiol 2000;83:1058-72. the first fMRI study in tinnitus, demonstrating alterations of auditory processing in inferior colliculus in tinnitus patients. [PubMed: 10669517]

22 *. Reyes SA, Salvi RJ, Burkard RF, Coad ML, Wack DS, Galantowicz PJ, et al. Brain imaging of the effects of lidocaine on tinnitus. Hear Res 2002;171:43-50. a PET study, that identified the neural correlates of lidocaine-induced tinnitus suppression. [PubMed: 12204348]

23. Langguth B, Eichhammer P, Kreutzer A, Maenner P, Marienhagen J, Kleinjung T, et al. The impact of auditory cortex activity on characterizing and treating patients with chronic tinnitus--first results from a PET study. Acta Otolaryngol Suppl 2006 Dec;(556):84-8. [PubMed: 17114149]

24. Smits M, Kovacs S, De RD, Peeters RR, Van HP, Sunaert S. Lateralization of functional magnetic resonance imaging (fMRI) activation in the auditory pathway of patients with lateralized tinnitus. Neuroradiology 2007 Aug;49(8):669-79. [PubMed: 17404721]

25 **. Schlee W, Hartmann T, Langguth B, Weisz N. Abnormal resting-state cortical coupling in chronic tinnitus. BMC Neurosci 2009;10(11) a very recent study that demonstrated alterations in neural connectivity between auditory and nonauditory brain areas in tinnitus patients. Furthermore it was demonstrated, that these patterns change over time.

26. Muroi Y, Chanda B. Local anesthetics disrupt energetic coupling between the voltage-sensing segments of a sodium channel. J Gen Physiol 2009 Jan;133(1):1-15. [PubMed: 19088384]

27 **. Trellakis S, Lautermann J, Lehnerdt G. Lidocaine: neurobiological targets and effects on the auditory system. Prog Brain Res 2007;166:303-22. an excellent review about the potential mechanisms by which lidocaine may reduce tinitus. [PubMed: 17956794]

28. Cronlein T, Langguth B, Geisler P, Hajak G. Tinnitus and insomnia. Prog Brain Res 2007;166:22733. [PubMed: 17956787]

29. Langguth B, Kleinjung T, Fischer B, Hajak G, Eichhammer P, Sand PG. Tinnitus severity, depression, and the big five personality traits. Prog Brain Res 2007;166:221-5. [PubMed: 17956786] 
30. Biassoni EC, Serra MR, Richtert U, Joekes S, Yacci MR, Carignani JA, et al. Recreational noise exposure and its effects on the hearing of adolescents. Part II: development of hearing disorders. Int J Audiol 2005 Feb;44(2):74-85. [PubMed: 15913155]

31. Serra MR, Biassoni EC, Richter U, Minoldo G, Franco G, Abraham S, et al. Recreational noise exposure and its effects on the hearing of adolescents. Part I: an interdisciplinary long-term study. Int J Audiol 2005 Feb;44(2):65-73. [PubMed: 15913154]

32 **. Dobie RA. A review of randomized clinical trials in tinnitus. Laryngoscope 1999;109:1202-11. an excellent review about aavailable randomized clinical trials for tinnitus, that also gives recommendation for future research strategies and clinical trial methodology. [PubMed: 10443820]

33. Dobie, R. Clinical Trials and Drug Therapy for Tinnitus. In: Snow, JB., editor. Tinnitus: Theory and Management. Hamilton: BC Decker; 2004. p. 266-77.

34 *. Vio, M. Tinnitus Market Situation Analysis. London: RNID; 2003. a market report for a virtual new tinnitus drug, provided by the Royal National Institute of Deafness (http://www.rnid.org.uk/marketreports)

35. Eggermont JJ. Tinnitus: neurobiological substrates. Drug Discov Today 2005 Oct 1;10(19):1283-90. [PubMed: 16214672]

36 *. Moller AR. Tinnitus and pain. Prog Brain Res 2007;166:47-53. a review that highlights similarities between tinnitus and chronic pain. [PubMed: 17956770]

37. Moller AR. A double-blind placebo-controlled trial of baclofen in the treatment of tinnitus. Am J Otol 1997 Mar;18(2):268-9. [PubMed: 9093691]

38. Barany R. Die Beeinflussung des Ohrensausens durch intravenös injizierte Lokalanästhetica. Acta Otolarngologica 1935;23:201-3.

39. Melding PS, Goodey RJ, Thorne PR. The use of intravenous lignocaine in the diagnosis and treatment of tinnitus. J Laryngol Otol 1978 Feb;92(2):115-21. [PubMed: 627764]

40. Martin FW, Colman BH. Tinnitus: a double-blind crossover controlled trial to evaluate the use of lignocaine. Clin Otolaryngol 1980;5:3-11. [PubMed: 6988115]

41. Sanchez TG, Balbani AP, Bittar RS, Bento RF, Camara J. Lidocaine test in patients with tinnitus: rationale of accomplishment and relation to the treatment with carbamazepine. Auris Nasus Larynx 1999 Oct;26(4):411-7. [PubMed: 10530736]

42. Trellakis S, Benzenberg D, Urban BW, Friederich P. Differential lidocaine sensitivity of human voltage-gated potassium channels relevant to the auditorysystem. Otol Neurotol 2006 Jan;27(1):11723. [PubMed: 16371858]

43. Haginomori S, Makimoto K, Araki M, Kawakami M, Takahashi H. Effect of lidocaine injection of EOAE in patients with tinnitus. Acta Otolaryngol $1995 \mathrm{Jul} ; 115(4): 488-92$. [PubMed: 7572122]

44 *. Baguley DM, Jones S, Wilkins I, Axon PR, Moffat DA. The inhibitory effect of intravenous lidocaine infusion on tinnitus after translabyrinthine removal of vestibular schwannoma: a doubleblind, placebo-controlled, crossover study. Otol Neurotol 2005 Mar;26(2):169-76. this study demonstrates that a cochlear effect of lidocaine is not necessary for tinnitus suppression. [PubMed: 15793400]

45. Schwartz ML, Meyer MB, Covino BG, Narang RM, Sethi V, Schwartz AJ, et al. Antiarrhythmic effectiveness of intramuscular lidocaine: influence of different injection sites. J Clin Pharmacol 1974 Feb;14(2):77-83. [PubMed: 4813081]

46. Clarkson CW, Follmer CH, Ten Eick RE, Hondeghem LM, Yeh JZ. Evidence for two components of sodium channel block by lidocaine in isolated cardiac myocytes. Circ Res 1988 Nov;63(5):86978. [PubMed: 2846199]

47. Courtney KR. Mechanism of frequency-dependent inhibition of sodium currents in frog myelinated nerve by the lidocaine derivative GEA. J Pharmacol Exp Ther 1975 Nov;195(2):225-36. [PubMed: 1081138]

48. Lenkowski PW, Shah BS, Dinn AE, Lee K, Patel MK. Lidocaine block of neonatal Nav1.3 is differentially modulated by co-expression of beta1 and beta3 subunits. Eur J Pharmacol 2003 Apr 25;467(1-3):23-30. [PubMed: 12706451]

49. Josephson IR. Lidocaine blocks Na, Ca and K currents of chick ventricular myocytes. J Mol Cell Cardiol 1988 Jul;20(7):593-604. [PubMed: 2459400] 
50. Plewnia C, Reimold M, Najib A, Brehm B, Reischl G, Plontke SK, et al. Dose-dependent attenuation of auditory phantom perception (tinnitus) by PET-guided repetitive transcranial magnetic stimulation. Hum Brain Mapp 2007 Mar;28(3):238-46. [PubMed: 16773635]

51. Hulshof JH, Vermeij P. The value of tocainide in the treatment of tinnitus. A double-blind controlled study. Arch Otorhinolaryngol 1985;241:279-83. [PubMed: 3161487]

52. Blayney AW, Phillips MS, Guy AM, Colman BH. A sequential double blind cross-over trial of tocainide hydrochloride in tinnitus. Clin Otolaryngol 1985;10:97-101. [PubMed: 3928215]

53. Lenarz T. Treatment of tinnitus with lidocaine and tocainide. Scand Audiol Suppl 1986;26:49-51. [PubMed: 3107115]

54. Sieghart W. Pharmacology of benzodiazepine receptors: an update. J Psychiatry Neurosci 1994 Jan; 19(1):24-9. [PubMed: 8148363]

55. Busto U, Fornazzari L, Naranjo CA. Protracted tinnitus after discontinuation of long-term therapeutic use of benzodiazepines. J Clin Psychopharmacol 1988 Oct;8(5):359-62. [PubMed: 2903182]

56. Busto U, Sellers EM, Naranjo CA, Cappell H, Sanchez-Craig M, Sykora K. Withdrawal reaction after long-term therapeutic use of benzodiazepines. N Engl J Med 1986 Oct 2;315(14):854-9. [PubMed: 3092053]

57. Johnson RM, Brummett R, Schleuning A. Use of alprazolam for relief of tinnitus. A double-blind study. Arch Otolaryngol Head Neck Surg 1993 Aug;119(8):842-5. [PubMed: 8343245]

58. Kay NJ. Oral chemotherapy in tinnitus. Br J Audiol 1981 May;15(2):123-4. [PubMed: 7225648]

59. Gananca MM, Caovilla HH, Gananca FF, Gananca CF, Munhoz MS, da Silva ML, et al. Clonazepam in the pharmacological treatment of vertigo and tinnitus. Int Tinnitus J 2002;8(1):50-3. [PubMed: 14763236]

60. Bahmad FM Jr, Venosa AR, Oliveira CA. Benzodiazepines and GABAergics in treating severe disabling tinnitus of predominantly cochlear origin. Int Tinnitus J 2006;12(2):140-4. [PubMed: 17260879]

61. Moller AR. Similarities between severe tinnitus and chronic pain. J Am Acad Audiol 2000;11:11524. [PubMed: 10755808]

62. Gross G, Xin X, Gastpar M. Trimipramine: pharmacological reevaluation and comparison with clozapine. Neuropharmacology 1991 Nov;30(11):1159-66. [PubMed: 1663593]

63. Bayar N, Boke B, Turan E, Belgin E. Efficacy of amitriptyline in the treatment of subjective tinnitus. J Otolaryngol 2001 Oct;30(5):300-3. [PubMed: 11771024]

64. Podoshin L, Ben-David Y, Fradis M, Malatskey S, Hafner H. Idiopathic Subjective Tinnitus Treated by Amitriptyline Hydrochloride/Biofeedback. Int Tinnitus J 1995;1(1):54-60. [PubMed: 10753321]

65. Sullivan MD, Dobie RA, Sakai CS, Katon WJ. Treatment of depressed tinnitus patients with nortriptyline. Ann Otol Rhinol Laryngol 1989 Nov;98(11):867-72. [PubMed: 2817678]

66. Sullivan M, Katon W, Russo J, Dobie R, Sakai C. A randomized trial of nortriptyline for severe chronic tinnitus. Effects on depression, disability, and tinnitus symptoms. Arch Intern Med 1993 Oct 11;153(19):2251-9. [PubMed: 8215728]

67. Katon W, Sullivan M, Russo J, Dobie R, Sakai C. Depressive symptoms and measures of disability: a prospective study. J Affect Disord 1993 Apr;27(4):245-54. [PubMed: 8509525]

68. Mihail RC, Crowley JM, Walden BE, Fishburne J, Reinwall JE, Zajtchuk JT. The tricyclic trimipramine in the treatment of subjective tinnitus. Ann Otol Rhinol Laryngol 1988 Mar;97(2 Pt 1): 120-3. [PubMed: 3355041]

69. Mendis D, Johnston M. An unusual case of prolonged tinnitus following low-dose amitriptyline. J Psychopharmacol 2008 Jul;22(5):574-5. [PubMed: 18308819]

70. Feder R. Tinnitus associated with amitriptyline. J Clin Psychiatry 1990 Feb;51(2):85-6. [PubMed: 2298710]

71. Tandon R, Grunhaus L, Greden JF. Imipramine and tinnitus. J Clin Psychiatry 1987 Mar;48(3):10911. [PubMed: 3818550]

72. Robinson SK, Viirre ES, Bailey KA, Gerke MA, Harris JP, Stein MB. Randomized placebo-controlled trial of a selective serotonin reuptake inhibitor in the treatment of nondepressed tinnitus subjects. Psychosom Med 2005 Nov;67(6):981-8. [PubMed: 16314604] 
73. Zoger S, Svedlund J, Holgers KM. The effects of sertraline on severe tinnitus suffering--a randomized, double-blind, placebo-controlled study. J Clin Psychopharmacol 2006 Feb;26(1):32-9. [PubMed: 16415703]

74 *. Robinson S. Antidepressants for treatment of tinnitus. Prog Brain Res 2007;166:263-71. a comprehensive review about the use of antidepressants for tinnitus. [PubMed: 17956790]

75. Willow M, Gonoi T, Catterall WA. Voltage clamp analysis of the inhibitory actions of diphenylhydantoin and carbamazepine on voltage-sensitive sodium channels in neuroblastoma cells. Mol Pharmacol 1985 May;27(5):549-58. [PubMed: 2581124]

76. Cardenas CA, Cardenas CG, de Armendi AJ, Scroggs RS. Carbamazepine interacts with a slow inactivation state of NaV1.8-like sodium channels. Neurosci Lett 2006 Nov 13;408(2):129-34. [PubMed: 16978779]

77. Shea JJ, Harell M. Management of tinnitus aurium with lidocaine and carbamazepine. Laryngoscope 1978 Sep;88(9 Pt 1):1477-84. [PubMed: 682804]

78. Melding PS, Goodey RJ. The treatment of tinnitus with oral anticonvulsants. J Laryngol Otol 1979 Feb;93(2):111-22. [PubMed: 429894]

79. Donaldson I. Tegretol: a double blind trial in tinnitus. J Laryngol Otol 1981 Sep;95(9):947-51. [PubMed: 7026707]

80. Hulshof JH, Vermeij P. The value of carbamazepine in the treatment of tinnitus. ORL J Otorhinolaryngol Relat Spec 1985;47:262-6. [PubMed: 3900856]

81. Marks NJ, Onisiphorou C, Trounce JR. The effect of single doses of amylobarbitone sodium and carbamazepine in tinnitus. J Laryngol Otol 1981 Sep;95(9):941-5. [PubMed: 7026706]

82. Levine RA. Typewriter tinnitus: a carbamazepine-responsive syndrome related to auditory nerve vascular compression. ORL J Otorhinolaryngol Relat Spec 2006;68(1):43-6. [PubMed: 16514262]

83 *. Mardini MK. Ear-clicking “tinnitus” responding to carbamazepine. N Engl J Med 1987 Dec 10;317 (24):1542. the first description of a specific tinnitus subtype which responds to carbamazepine treatment. [PubMed: 3683492]

84. Zheng Y, Hooton K, Smith PF, Darlington CL. Carbamazepine reduces the behavioural manifestations of tinnitus following salicylate treatment in rats. Acta Otolaryngol $2008 \mathrm{Jan} ; 128(1)$ : 48-52. [PubMed: 17851905]

85. Zapp JJ. Gabapentin for the treatment of tinnitus: a case report. Ear Nose Throat J 2001 Feb;80(2): 114-6. [PubMed: 11233342]

86. Shulman A. Gabapentin and tinnitus relief. Int Tinnitus J 2008;14(1):1-5. [PubMed: 18616079]

87. Bauer CA, Brozoski TJ. Assessing tinnitus and prospective tinnitus therapeutics using a psychophysical animal model. J Assoc Res Otolaryngol 2001 Mar;2(1):54-64. [PubMed: 11545150]

88. Witsell DL, Hannley MT, Stinnet S, Tucci DL. Treatment of tinnitus with gabapentin: a pilot study. Otol Neurotol 2007 Jan;28(1):11-5. [PubMed: 17106432]

89. Bakhshaee M, Ghasemi M, Azarpazhooh M, Khadivi E, Rezaei S, Shakeri M, et al. Gabapentin effectiveness on the sensation of subjective idiopathic tinnitus: a pilot study. Eur Arch Otorhinolaryngol 2008 May;265(5):525-30. [PubMed: 17960408]

90. Piccirillo JF, Finnell J, Vlahiotis A, Chole RA, Spitznagel E Jr. Relief of idiopathic subjective tinnitus: is gabapentin effective? Arch Otolaryngol Head Neck Surg 2007 Apr;133(4):390-7. [PubMed: 17438255]

91. Bauer CA, Brozoski TJ. Effect of gabapentin on the sensation and impact of tinnitus. Laryngoscope 2006 May;116(5):675-81. [PubMed: 16652071]

92. Brozoski TJ, Spires TJ, Bauer CA. Vigabatrin, a GABA transaminase inhibitor, reversibly eliminates tinnitus in an animal model. J Assoc Res Otolaryngol 2007 Mar;8(1):105-18. [PubMed: 17221143]

93. Willmore LJ, Abelson MB, Ben-Menachem E, Pellock JM, Shields WD. Vigabatrin: 2008 update. Epilepsia 2009 Feb;50(2):163-73. [PubMed: 19230067]

94. Oestreicher E, Arnold W, Ehrenberger K, Felix D. Memantine suppresses the glutamatergic neurotransmission of mammalian inner hair cells. ORL J Otorhinolaryngol Relat Spec 1998 Jan;60 (1):18-21. [PubMed: 9519376] 
95. Guitton MJ, Caston J, Ruel J, Johnson RM, Pujol R, Puel JL. Salicylate induces tinnitus through activation of cochlear NMDA receptors. J Neurosci 2003 May 1;23(9):3944-52. [PubMed: 12736364]

96. Guitton MJ, Dudai Y. Blockade of cochlear NMDA receptors prevents long-term tinnitus during a brief consolidation window after acoustic trauma. Neural Plast 2007;2007:80904. [PubMed: 18301716]

97 **. Jastreboff PJ, Brennan JF, Coleman JK, Sasaki CT. Phantom auditory sensation in rats: an animal model for tinnitus. Behav Neurosci 1988 Dec;102(6):811-22. the first description of an animal model of tinnitus. [PubMed: 3214530]

98. Peng BG, Chen S, Lin X. Aspirin selectively augmented N-methyl-D-aspartate types of glutamate responses in cultured spiral ganglion neurons of mice. Neurosci Lett 2003 May 29;343(1):21-4. [PubMed: 12749988]

99. Ehrenberger K, Felix D. Receptor pharmacological models for inner ear therapies with emphasis on glutamate receptors: a survey. Acta Otolaryngol 1995;115:236-40. [PubMed: 7610812]

100. Denk DM, Heinzl H, Franz P, Ehrenberger K. Caroverine in tinnitus treatment. A placebo-controlled blind study. Acta Otolaryngol 1997 Nov;117(6):825-30. [PubMed: 9442821]

101. Domeisen H, Hotz MA, Hausler R. Caroverine in tinnitus treatment. Acta Otolaryngol 1998 Jul;118 (4):606-8. [PubMed: 9726691]

102. Rogawski MA, Wenk GL. The neuropharmacological basis for the use of memantine in the treatment of Alzheimer's disease. CNS Drug Rev 2003;9(3):275-308. [PubMed: 14530799]

103. Rammes G, Rupprecht R, Ferrari U, Zieglgansberger W, Parsons CG. The N-methyl-D-aspartate receptor channel blockers memantine, MRZ 2/579 and other amino-alkyl-cyclohexanes antagonise 5-HT(3) receptor currents in cultured HEK-293 and N1E-115 cell systems in a non-competitive manner. Neurosci Lett 2001 Jun 22;306(1-2):81-4. [PubMed: 11403963]

104. Oliver D, Ludwig J, Reisinger E, Zoellner W, Ruppersberg JP, Fakler B. Memantine inhibits efferent cholinergic transmission in the cochlea by blocking nicotinic acetylcholine receptors of outer hair cells. Mol Pharmacol 2001 Jul;60(1):183-9. [PubMed: 11408613]

105. Lobarinas E, Yang G, Sun W, Ding D, Mirza N, by-Brown W, et al. Salicylate- and quinine-induced tinnitus and effects of memantine. Acta Otolaryngol Suppl 2006 Dec;(556):13-9. [PubMed: 17114137]

106. Figueiredo RR, Langguth B, de Oliveira PM, de Azevedo AA. Tinnitus treatment with memantine. Otolaryngol Head Neck Surg 2008 Apr;138(4):492-6. [PubMed: 18359360]

107. Salembier L, De Ridder D, Van de Heyning PH. The use of flupirtine in treatment of tinnitus. Acta Otolaryngol Suppl 2006 Dec;(556):93-5. [PubMed: 17114151]

108. Williams SH. Medications for treating alcohol dependence. Am Fam Physician 2005 Nov 1;72(9): 1775-80. [PubMed: 16300039]

109. Azevedo AA, Figueiredo RR. Treatment of tinnitus with acamprosate. Prog Brain Res 2007;166:273-7. [PubMed: 17956791]

110. Jastreboff PJ, Hazell JW. A neurophysiological approach to tinnitus: clinical implications. Br J Audiol 1993 Feb;27(1):7-17. [PubMed: 8339063]

111 *. Lockwood AH, Salvi RJ, Coad ML, Towsley ML, Wack DS, Murphy BW. The functional neuroanatomy of tinnitus: evidence for limbic system links and neural plasticity. Neurology 1998 Jan;50(1):114-20. a PET study, that demonstrated clearly the involvement of limbic brain areas in the pathophysiology of tinnitus. [PubMed: 9443467]

112. Larson ER, Ariano MA. D3 and D2 dopamine receptors: visualization of cellular expression patterns in motor and limbic structures. Synapse 1995 Aug;20(4):325-37. [PubMed: 7482292]

113. Memo M, Battaini F, Spano PF, Trabucchi M. Sulpiride and the role of dopaminergic receptor blockade in the antipsychotic activity of neuroleptics. Acta Psychiatr Scand 1981 Apr;63(4):31424. [PubMed: 7315480]

114. Lopez-Gonzalez MA, Santiago AM, Esteban-Ortega F. Sulpiride and melatonin decrease tinnitus perception modulating the auditolimbic dopaminergic pathway. J Otolaryngol 2007 Aug;36(4): 213-9. [PubMed: 17942035]

115. Lopez-Gonzalez MA, Moliner-Peiro F, faro-Garcia J, Esteban-Ortega F. Sulpiride plus hydroxyzine decrease tinnitus perception. Auris Nasus Larynx 2007 Mar;34(1):23-7. [PubMed: 17118597] 
116. Hastak SM. Treatment of memory impairment, vertigo and tinnitus in the elderly with piribedil in an Indian general practice setting. J Indian Med Assoc 2003 Aug;101(8):500-1. [PubMed: 15071809]

117. Azevedo AA, Langguth B, de Oliveira PM, Figueiredo RR. Tinnitus treatment with piribedil guided by electrocochleography and acoustic otoemisions. Otol Neurotol. 2009 In press.

118. Slattery WH, Fisher LM, Iqbal Z, Friedman RA, Liu N. Intratympanic steroid injection for treatment of idiopathic sudden hearing loss. Otolaryngol Head Neck Surg 2005 Aug;133(2):251-9. [PubMed: 16087024]

119. Slattery WH, Fisher LM, Iqbal Z, Liu N. Oral steroid regimens for idiopathic sudden sensorineural hearing loss. Otolaryngol Head Neck Surg 2005 Jan;132(1):5-10. [PubMed: 15632902]

120. Haynes DS, O’Malley M, Cohen S, Watford K, Labadie RF. Intratympanic dexamethasone for sudden sensorineural hearing loss after failure of systemic therapy. Laryngoscope 2007 Jan;117(1): 3-15. [PubMed: 17202923]

121 *. Wei PBC, Mubiru S, O'Leary S. Steroids for idiopathic sudden sensorineural hearing loss. Cochrane Database of Systematic Reviews. 2006 Cochrane review about the use of steroids for the treatment of sudden sensorineural hearing loss.

122. Mahadevan S, Park Y. Multifaceted therapeutic benefits of Ginkgo biloba L.: chemistry, efficacy, safety, and uses. J Food Sci 2008 Jan;73(1):R14-R19. [PubMed: 18211362]

123. Morgenstern C, Biermann E. The efficacy of Ginkgo special extract EGb 761 in patients with tinnitus. Int J Clin Pharmacol Ther 2002 May;40(5):188-97. [PubMed: 12051570]

124. Holstein N. Ginkgo special extract EGb 761 in tinnitus therapy. An overview of results of completed clinical trials. Fortschr Med Orig 2001;118:157-64. [PubMed: 11217680]

125. Drew S, Davies E. Effectiveness of Ginkgo biloba in treating tinnitus: double blind, placebo controlled trial. Bmj 2001 Jan 13;322(7278):73. [PubMed: 11154618]

126. Rejali D, Sivakumar A, Balaji N. Ginkgo biloba does not benefit patients with tinnitus: a randomized placebo-controlled double-blind trial and meta-analysis of randomized trials. Clin Otolaryngol Allied Sci 2004 Jun;29(3):226-31. [PubMed: 15142066]

127 *. Hilton M, Stuart E. Ginkgo biloba for tinnitus. Cochrane Database Syst Rev 2004;(2):CD003852. Cochrane review about the use of Ginkgo biloba for the treatment of tinnitus. The conclusion is that there is no evidence for a benefit of Ginkgo biloba in the treatment of tinnitus. [PubMed: 15106224]

128. Jan JE, Reiter RJ, Wasdell MB, Bax M. The role of the thalamus in sleep, pineal melatonin production, and circadian rhythm sleep disorders. J Pineal Res 2009 Jan;46(1):1-7. [PubMed: 18761566]

129. Seggie J, Werstiuk ES, Grota L. Lithium and circadian patterns of melatonin in the retina, hypothalamus, pineal and serum. Prog Neuropsychopharmacol Biol Psychiatry 1987;11(2-3):32534. [PubMed: 2819953]

130. Berra B, Rizzo AM. Melatonin: circadian rhythm regulator, chronobiotic, antioxidant and beyond. Clin Dermatol 2009 Mar;27(2):202-9. [PubMed: 19168001]

131. Lopez-Gonzalez MA, Guerrero JM, Rojas F, Delgado F. Ototoxicity caused by cisplatin is ameliorated by melatonin and other antioxidants. J Pineal Res 2000 Mar;28(2):73-80. [PubMed: 10709968]

132. Bas E, Martinez-Soriano F, Lainez JM, Marco J. An experimental comparative study of dexamethasone, melatonin and tacrolimus in noise-induced hearing loss. Acta Otolaryngol 2009 Apr;129(4):385-9. [PubMed: 19051071]

133. Megwalu UC, Finnell JE, Piccirillo JF. The effects of melatonin on tinnitus and sleep. Otolaryngol Head Neck Surg 2006 Feb;134(2):210-3. [PubMed: 16455366]

134. Rosenberg SI, Silverstein H, Rowan PT, Olds MJ. Effect of melatonin on tinnitus. Laryngoscope 1998 Mar;108(3):305-10. [PubMed: 9504599]

135. McFadden SL, Ding D, Burkard RF, Jiang H, Reaume AG, Flood DG, et al. Cu/Zn SOD deficiency potentiates hearing loss and cochlear pathology in aged 129,CD-1 mice. J Comp Neurol 1999 Oct 11;413(1):101-12. [PubMed: 10464373]

136. Zirpel L, Parks TN. Zinc inhibition of group I mGluR-mediated calcium homeostasis in auditory neurons. J Assoc Res Otolaryngol 2001 Jun;2(2):180-7. [PubMed: 11550527] 
137. Shambaugh GE Jr. Zinc for tinnitus, imbalance, and hearing loss in the elderly. Am J Otol 1986 Nov;7(6):476-7. [PubMed: 3492920]

138. Coelho CB, Tyler R, Hansen M. Zinc as a possible treatment for tinnitus. Prog Brain Res 2007;166:279-85. [PubMed: 17956792]

139. Paaske PB, Pedersen CB, Kjems G, Sam IL. Zinc in the management of tinnitus. Placebo-controlled trial. Ann Otol Rhinol Laryngol 1991 Aug;100(8):647-9. [PubMed: 1872515]

140. Yetiser S, Tosun F, Satar B, Arslanhan M, Akcam T, Ozkaptan Y. The role of zinc in management of tinnitus. Auris Nasus Larynx 2002 Oct;29(4):329-33. [PubMed: 12393036]

141. Roth SH. Misoprostol in the prevention of NSAID-induced gastric ulcer: a multicenter, doubleblind, placebo-controlled trial. J Rheumatol Suppl 1990 Feb;20:20-4. [PubMed: 2109073]

142. Briner W, House J, O'Leary M. Synthetic prostaglandin E1 misoprostol as a treatment for tinnitus. Arch Otolaryngol Head Neck Surg 1993 Jun;119(6):652-4. [PubMed: 8499097]

143. Yilmaz I, Akkuzu B, Cakmak O, Ozluoglu LN. Misoprostol in the treatment of tinnitus: a doubleblind study. Otolaryngol Head Neck Surg 2004 May;130(5):604-10. [PubMed: 15138428]

144. Gresser U, Gathof BS. Atorvastatin: gold standard for prophylaxis of myocardial ischemia and stroke - comparison of the clinical benefit of statins on the basis of randomized controlled endpoint studies. Eur J Med Res 2004 Jan 26;9(1):1-17. [PubMed: 14766335]

145. Olzowy B, Canis M, Hempel JM, Mazurek B, Suckfull M. Effect of atorvastatin on progression of sensorineural hearing loss and tinnitus in the elderly: results of a prospective, randomized, doubleblind clinical trial. Otol Neurotol 2007 Jun;28(4):455-8. [PubMed: 17529847]

146. Scriabine A, van den KW. Pharmacology of nimodipine. A review. Ann N Y Acad Sci 1988;522:698-706. [PubMed: 3288065]

147. Keyrouz SG, Diringer MN. Clinical review: Prevention and therapy of vasospasm in subarachnoid hemorrhage. Crit Care 2007;11(4):220. [PubMed: 17705883]

148. Goodnick PJ. Nimodipine treatment of rapid cycling bipolar disorder. J Clin Psychiatry 1995 Jul; 56(7):330. [PubMed: 7615488]

149. Jastreboff PJ, Brennan JF, Sasaki CT. Quinine-induced tinnitus in rats. Arch Otolaryngol Head Neck Surg 1991 Oct;117(10):1162-6. [PubMed: 1910705]

150. Theopold, HM. Laryngol Rhinol Otol. Vol. 64. Stuttg: 1985 Dec. Nimodipine (Bay e 9736) a new therapy concept in diseases of the inner ear?; p. 609-13.

151. Davies E, Knox E, Donaldson I. The usefulness of nimodipine, an L-calcium channel antagonist, in the treatment of tinnitus. Br J Audiol 1994 Jun;28(3):125-9. [PubMed: 7841896]

152. Hutcheon DE, Leonard G. Diuretic and antihypertensive actions of furosemide. J Clin Pharmacol J New Drugs 1967 Jan;7(1):26-33. [PubMed: 5317540]

153. Shiozaki A, Miyazaki H, Niisato N, Nakahari T, Iwasaki Y, Itoi H, et al. Furosemide, a blocker of $\mathrm{Na}+/ \mathrm{K}+/ 2 \mathrm{Cl}-$ cotransporter, diminishes proliferation of poorly differentiated human gastric cancer cells by affecting G0/G1 state. J Physiol Sci 2006 Dec;56(6):401-6. [PubMed: 17052386]

154. Sakaguchi N, Crouch JJ, Lytle C, Schulte BA. Na-K-Cl cotransporter expression in the developing and senescent gerbil cochlea. Hear Res 1998 Apr;118(1-2):114-22. [PubMed: 9606066]

155. Chen H, Sun D. The role of Na-K-Cl co-transporter in cerebral ischemia. Neurol Res 2005 Apr;27 (3):280-6. [PubMed: 15845211]

156. Rybak LP, Morizono T. Effect of furosemide upon endolymph potassium concentration. Hear Res 1982 Jul;7(2):223-31. [PubMed: 6286585]

157. Futaki T, Kitahara M, Morimoto M. A comparison of the furosemide and glycerol tests for Meniere's disease. With special reference to the bilateral lesion. Acta Otolaryngol 1977 Mar;83(3-4):272-8. [PubMed: 857600]

158. Kuchar DL, O’Rourke MF. High dose furosemide in refractory cardiac failure. Eur Heart J 1985 Nov;6(11):954-8. [PubMed: 4076205]

159. Ho KM, Sheridan DJ. Meta-analysis of frusemide to prevent or treat acute renal failure. Bmj 2006 Aug 26;333(7565):420. [PubMed: 16861256]

160. Filipo R, Barbara M, Cordier A, Mafera B, Romeo R, Attanasio G, et al. Osmotic drugs in the treatment of cochlear disorders: a clinical and experimental study. Acta Otolaryngol 1997 Mar;117 (2):229-31. [PubMed: 9105456] 
161. McCabe BF. Central aspects of drugs for motion sickness and vertigo. Adv Otorhinolaryngol 1973;20:458-69. [PubMed: 4575761]

162. Kranke P, Morin AM, Roewer N, Wulf H, Eberhart LH. The efficacy and safety of transdermal scopolamine for the prevention of postoperative nausea and vomiting: a quantitative systematic review. Anesth Analg 2002 Jul;95(1):133-43. table. [PubMed: 12088957]

163. Wallhausser-Franke E, Cuautle-Heck B, Wenz G, Langner G, Mahlke C. Scopolamine attenuates tinnitus-related plasticity in the auditory cortex. Neuroreport 2006 Oct 2;17(14):1487-91. [PubMed: 16957594]

164. Lobarinas E, Sun W, Stolzberg D, Lu J, Salvi R. Human Brain Imaging of Tinnitus and Animal Models. Semin Hear 2008 Nov;29(4):333-49. [PubMed: 19122834]

165. Timmerman H. Calcium modulation and clinical effect. Profile of cyclandelate. Drugs 1987;33 ( Suppl 2):1-4. [PubMed: 3622303]

166. Memin Y. Perceived efficacy of cyclandelate in the treatment of cochleovestibular and retinal disturbances related to cerebrovascular insufficiency. A study in general practice comprising 2772 patients. Drugs 1987;33( Suppl 2):120-4. [PubMed: 3497796]

167. Hester TO, Theilman G, Green W, Jones RO. Cyclandelate in the management of tinnitus: a randomized, placebo-controlled study. Otolaryngol Head Neck Surg 1998 Mar;118(3 Pt 1):329_ 32. [PubMed: 9527112]

168. Stidham KR, Solomon PH, Roberson JB. Evaluation of botulinum toxin A in treatment of tinnitus. Otolaryngol Head Neck Surg 2005 Jun;132(6):883-9. [PubMed: 15944559]

169. Penney SE, Bruce IA, Saeed SR. Botulinum toxin is effective and safe for palatal tremor: a report of five cases and a review of the literature. J Neurol 2006 Jul;253(7):857-60. [PubMed: 16845571]

170. Adjamian P, Sereda M, Hall DA. The mechanisms of tinnitus: Perspectives from human functional neuroimaging. Hear Res . 2009 Apr 11;

$171 * *$. Turner JG. Behavioral measures of tinnitus in laboratory animals. Prog Brain Res 2007;166:14756. this article describes the use of the startle reflex and its inhibition by gap detection as a behavioural measure of tinnitus, which does not require any training. [PubMed: 17956779]

172 **. Arnold W, Bartenstein P, Oestreicher E, Romer W, Schwaiger M. Focal metabolic activation in the predominant left auditory cortex in patients suffering from tinnitus: a PET study with [18F] deoxyglucose. ORL J Otorhinolaryngol Relat Spec 1996;58:195-9. a functional imaging study, that describes for the first time alterations of metabolic activity in the auditory cortex of tinnitus patients. [PubMed: 8883104]

173 **. Muhlnickel W, Elbert T, Taub E, Flor H. Reorganization of auditory cortex in tinnitus. Proc Natl Acad Sci U S A 1998;95:10340-3. a magnetetcephalographic study, that describes alterations of the tonotopic map in the auditory cortex of tinnitus patients, suggesting similarities between tinnitus and phantom limb pain. [PubMed: 9707649]

174. Sun W, Lu J, Stolzberg D, Gray L, Deng A, Lobarinas E, et al. Salicylate increases the gain of the central auditory system. Neuroscience 2009 Mar 3;159(1):325-34. [PubMed: 19154777]

175. Moller AR. The role of neural plasticity in tinnitus. Prog Brain Res 2007;166:37-45. [PubMed: 17956769]

176. De Ridder D, Verstraeten E, Van der KK, De Mulder G, Sunaert S, Verlooy J, et al. Transcranial magnetic stimulation for tinnitus: influence of tinnitus duration on stimulation parameter choice and maximal tinnitus suppression. Otol Neurotol 2005 Jul;26(4):616-9. [PubMed: 16015156]

177. De Ridder D, van der Loo E, Van der Kelen K, Menovsky T, Van de Heyning P, Moller A. Do tonic and burst TMS modulate the lemniscal and extralemniscal system differentially? Int J Med Sci 2007;4(5):242-6. [PubMed: 17952200]

178 **. Tyler R, Coelho C, Tao P, Ji H, Noble W, Gehringer A, et al. Identifying tinnitus subgroups with cluster analysis. Am J Audiol 2008 Dec;17(2):S176-S184. an approach for subtyping tinnitus patients based on a combination of clinical characteristics. [PubMed: 19056922]

179. Tyler RS, Oleson J, Noble W, Coelho C, Ji H. Clinical trials for tinnitus: study populations, designs, measurement variables, and data analysis. Prog Brain Res 2007;166:499-509. [PubMed: 17956814]

180. Elgoyhen AB, Vetter DE, Katz E, Rothlin CV, Heinemann SF, Boulter J. alpha10: a determinant of nicotinic cholinergic receptor function in mammalian vestibular and cochlear mechanosensory hair cells. Proc Natl Acad Sci U S A 2001 Mar 13;98(6):3501-6. [PubMed: 11248107] 
181. Elgoyhen AB, Johnson DS, Boulter J, Vetter DE, Heinemann S. Alpha 9: an acetylcholine receptor with novel pharmacological properties expressed in rat cochlear hair cells. Cell 1994 Nov 18;79(4): 705-15. [PubMed: 7954834]

182. Plazas PV, Savino J, Kracun S, Gomez-Casati ME, Katz E, Parsons CG, et al. Inhibition of the alpha9alpha10 nicotinic cholinergic receptor by neramexane, an open channel blocker of N-methylD-aspartate receptors. Eur J Pharmacol 2007 Jul 2;566(1-3):11-9. [PubMed: 17466293]

183. Sun W, Ding DL, Wang P, Sun J, Jin X, Salvi RJ. Substance P inhibits potassium and calcium currents in inner ear spiral ganglion neurons. Brain Res 2004 Jun 25;1012(1-2):82-92. [PubMed: 15158164]

184. Carpenter WT, Koenig JI. The evolution of drug development in schizophrenia: past issues and future opportunities. Neuropsychopharmacology 2008 Aug;33(9):2061-79. [PubMed: 18046305]

185. De Ridder D, Fransen H, Francois O, Sunaert S, Kovacs S, Van de Heyning P. Amygdalohippocampal involvement in tinnitus and auditory memory. Acta Otolaryngol Suppl 2006 Dec;(556):50-3. [PubMed: 17114143]

186. Yang G, Lobarinas E, Zhang L, Turner J, Stolzberg D, Salvi R, et al. Salicylate induced tinnitus: behavioral measures and neural activity in auditory cortex of awake rats. Hear Res 2007 Apr;226 (1-2):244-53. [PubMed: 16904853]

187. Lobarinas E, Sun W, Cushing R, Salvi R. A novel behavioral paradigm for assessing tinnitus using schedule-induced polydipsia avoidance conditioning (SIP-AC). Hear Res 2004 Apr;190(1-2):10914. [PubMed: 15051133]

188. Hurko O, Ryan JL. Translational research in central nervous system drug discovery. NeuroRx 2005 Oct;2(4):671-82. [PubMed: 16489374]

189. Meikle MB, Vernon J, Johnson RM. The perceived severity of tinnitus. Some observations concerning a large population of tinnitus clinic patients. Otolaryngol Head Neck Surg 1984 Dec; 92(6):689-96. [PubMed: 6440089]

190. Jakes SC, Hallam RS, Chambers C, Hinchcliffe R. A factor analytical study of tinnitus complaint behaviour. Audiology 1985;24(3):195-206. [PubMed: 4004646]

191. Newman CW, Sandridge SA, Jacobson GP. Psychometric adequacy of the Tinnitus Handicap Inventory (THI) for evaluating treatment outcome. J Am Acad Audiol 1998 Apr;9(2):153-60. [PubMed: 9564679]

192. Goebel G, Hiller W. The tinnitus questionnaire. A standard instrument for grading the degree of tinnitus. Results of a multicenter study with the tinnitus questionnaire. Hno 1994;42:166-72. [PubMed: 8175381]

193. Kuk FK, Tyler RS, Russell D, Jordan H. The psychometric properties of a tinnitus handicap questionnaire. Ear Hear 1990 Dec;11(6):434-45. [PubMed: 2073977] 
Table 1

Number of prescriptions prescribed in 2001 in primary care for the diagnosis of tinnitus in Western Europe *.

\begin{tabular}{ll}
\hline Substance & Number of prescriptions in 2001 (in Thousands) \\
ginkgo biloba & 782 \\
trimetazidine & 650 \\
betahistine & 314 \\
pentoxifylline & 312 \\
piracetam & 197 \\
naftidrofuryl & 184 \\
buflomedil & 144 \\
cinnarizine & 141 \\
clonazepam & 137 \\
nicergoline & 119 \\
dihydroergocristine & 91 \\
flunarizine & 73 \\
nimodipine & 56 \\
Acetylsalicylic acid & 53 \\
hetastarch & 50 \\
ajmalicine & 42 \\
moxaverine & 32 \\
piribedil & 31 \\
almitrine & 21 \\
prednisolone & 21 \\
amitriptyline & 21 \\
dihydroergocryptine & 18 \\
cinnarizine & 18 \\
caffeine & 10 \\
mesoglicane & 14 \\
Vitamin E & 14 \\
dihydroergotixine & 14 \\
retinol & 13 \\
cyclandelate & Gold \\
Viscum album & 10 \\
\hline
\end{tabular}

Number of prescriptions prescribed in 2001 in primary care for diagnosis of tinnitus in Western Europe (UK, France, Germany, Spain, Italy, Netherlands, Belgium, Denmark, Finland, Austria, Greece, Portugal, Republic of Ireland and Switzerland) (only substances with at least 10000 prescriptions are included) 

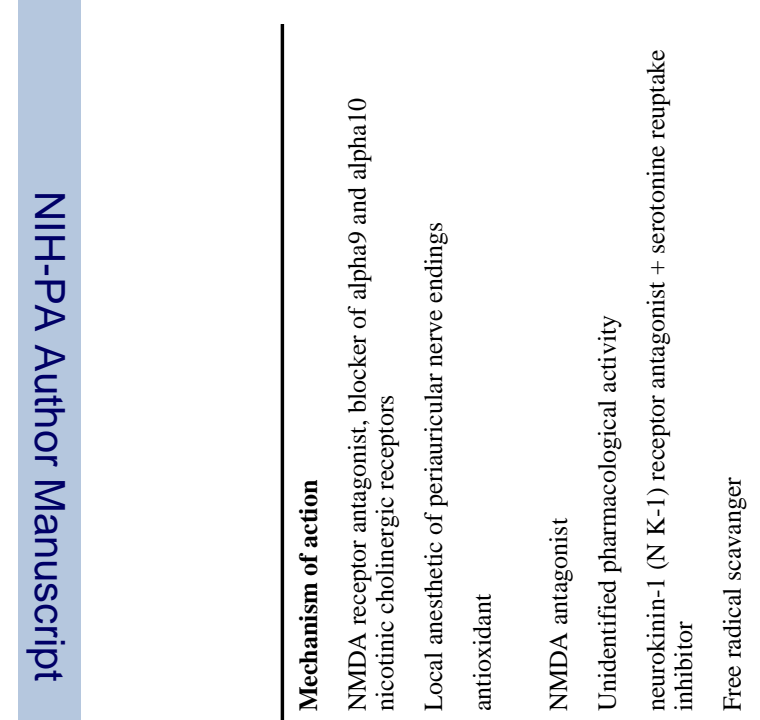